\title{
Is bipolar always bipolar? Understanding the controversy on bipolar disorder in children Yvonne Grimmer ${ }^{1}$, Sarah Hohmann ${ }^{1}$ and Luise Poustka ${ }^{1,2 *}$
}

\author{
Addresses: ${ }^{1}$ Department of Child and Adolescent Psychiatry and Psychotherapy, Central Institute of Mental Health, Medical Faculty Mannheim, \\ University of Heidelberg, J5, 68159, Mannheim, Germany; ${ }^{2}$ Department of Psychiatry and Psychotherapy, Medical University of Vienna, \\ Waehringer Guertel 18-20, A-1090, Vienna, Austria \\ * Corresponding author: Luise Poustka (luise.poustka@zi-mannheim.de) \\ FI000Prime Reports 2014, 6:III (doi:10.12703/P6-III) \\ All F1000Prime Reports articles are distributed under the terms of the Creative Commons Attribution-Non Commercial License \\ (http://creativecommons.org/licenses/by-nc/3.0/legalcode), which permits non-commercial use, distribution, and reproduction in any medium, \\ provided the original work is properly cited. \\ The electronic version of this article is the complete one and can be found at: http://fl000.com/prime/reports/m/6/III
}

\begin{abstract}
Dramatically increasing prevalence rates of bipolar disorder in children and adolescents in the United States have provoked controversy regarding the boundaries of manic symptoms in child and adolescent psychiatry. The serious impact of this ongoing debate on the treatment of affected children is reflected in the concomitant increase in prescription rates for antipsychotic medication.

A key question in the debate is whether this increase in bipolar disorder in children and adolescents is based on a better detection of early-onset bipolar disorder-which can present differently in children and adolescents - or whether it is caused by an incorrect assignment of symptoms which overlap with other widely known disorders.

So far, most findings suggest that the suspected symptoms, in particular chronic, non-episodic irritability (a mood symptom presenting with easy annoyance, temper tantrums and anger) do not constitute a developmental presentation of childhood bipolar disorder. Additional research based on prospective, longitudinal studies is needed to further clarify the developmental trajectories of bipolar disorder and the diagnostic status of chronic, non-episodic irritability.
\end{abstract}

\section{Introduction and context}

Over the last 20 years, the prevalence of bipolar disorder in children has risen rapidly in the United States (from $0.42 \%$ [ $n=25]$ in 1994 to $6.7 \%$ [ $n=1003]$ in $2003[1,2])$, while the overall incidence of a bipolar diagnosis in children in Germany and other European countries has remained low [3-5]. Although recent data suggest more stable international prevalence rates with a wider range of variation $(0.1 \%$ to $6.7 \%$ in the United States) [6], the high prevalence and the concomitantly increasing use of antipsychotic medication [7] has been a cause for concern to scientists and clinicians alike. Discussion has arisen as to whether this increase of bipolar disorder is simply due to a better detection of early developmental stages of the disorder, or whether it reflects a completely different phenomenon, which overlaps with symptom domains of other psychiatric disorders.
According to longitudinal studies, almost three in four adults affected by psychiatric disorders had diagnosable psychiatric syndromes before the age of 18 , and almost half of them before the age of 15 (Dunedin longitudinal cohort study [8]). Some adult disorders were preceded by their juvenile counterparts (e.g. in the Dunedin study, adult anxiety was often preceded by juvenile anxiety), but in several cases, the nature of childhood psychopathology differed substantially from that of the adult disorder (heterotypic development) [9]. Schizophreniform disorders, for example, are preceded by a broad array of juvenile disorders, including juvenile anxiety and depression as well as attention deficit hyperactivity disorder (ADHD) and oppositional defiant disorder (ODD) [8].

In many mental disorders, early onset is often associated with poor outcome. Perlis et al. reported in a large group of 
adults $(n=1000)$ that the early-onset of bipolar disorder is common and associated with greater rates of comorbidity, more relapses and a greater likelihood of suicide attempts and violence (Systematic Treatment Enhancement Program for Bipolar Disorder [STEP-BD]) [10]. In another study, delay of treatment was followed by a more severe illness course [11].

To avoid treatment delay and, in consequence, an unfavorable outcome, it is of particular importance to select those children at risk for early-onset bipolar disorder. On the other hand, over-diagnosing might lead to incorrect treatment with the risk of long-term side effects for children, who might have had more benefit from less invasive treatments.

With regard to bipolar disorder, some scientists have pointed out that chronic, non-episodic irritability-a mood symptom presenting with easy annoyance and temper tantrums [12] -is also a feature of bipolar disorder in children. Based on this viewpoint, bipolar disorder should not be uncommon in this age group; it may include very fast mood swings (as often as two to three times a day [13]) and a non-episodic course. Furthermore, there have been claims that mania might be misdiagnosed as ADHD in childhood and vice versa, as the two conditions share features, such as hyperactivity, distractibility, excessive talking and reduced inhibition [14].

Given the importance of a proper diagnosis in childhood, it is worth taking a closer look at the background of this ongoing debate. Therefore, the present article reviews the latest literature on the discussion on pediatric bipolar disorder and outlines relevant neurobiological evidence and treatment implications.

\section{Classical bipolar disorder}

According to the Diagnostic and statistical manual of mental disorders (DSM)-5, a diagnosis of mania requires distinct episodes of "abnormally elevated, expansive or irritable mood and abnormally and persistently increased goal-directed activity or energy", on seven consecutive days for mania and 4 days for hypomania, and three (four if the mood is only irritable) so-called B symptoms, such as inflated self-esteem, decreased need for sleep, increased goal-directed or psychomotor activity, pressured speech, flight of ideas and increased distractibility. In addition, high-risk behavior, sexual disinhibition or psychotic symptoms may occur. To enhance the accuracy of diagnosis, an emphasis on the changes in activity and energy as well as mood was included in DSM-5. The diagnosis of bipolarity now requires, as entry criterion $\mathrm{A}$, not only the presence of an elated and irritable mood, but also the association of these symptoms with increased energy/activity (for full criteria see DSM-5 [15]).

Episodic irritability, lasting 4-7 days and, in most cases, combined with elation is a core symptom of childhood bipolar disorder. Still, it is important to consider the heterogeneity of irritability as a phenomenon observable in various child psychiatric disorders, such as ODD, major depression, generalized anxiety, ADHD and post-traumatic stress disorder. Therefore, nonepisodic irritability has low specificity for bipolar disorder [16,17]. The American Academy of Child and Adolescent Psychiatry (AACAP) guidelines on pediatric bipolar disorder [18] recommend in the first place focusing on the determination of episodes and, secondly, ascertaining manic symptoms in the identified time frame.

Children suffering from classical bipolar disorder are characterized by poor outcome, frequent family history of the disorder and high continuity over the lifespan [19]. Prevalence rates of classical bipolar disorder in children remain stable at a very low level $(0.1 \%$ in children aged 9-13 years of age [20]; $1.2 \%$ in a community study, agegroup 8-19 [21]), but bipolar disorder becomes more common in adolescents $(2.9 \%$ [22] to 6.7\% [23], agegroup 14-18). Children with bipolar disorder are known to suffer from several comorbidities, most frequently ADHD, anxiety disorders, ODD or conduct disorder in adolescents [17].

Limited but crucial research in high-risk families has provided valuable information about early developmental stages and precursors of bipolar disorder: findings from a longitudinal study following the offspring in high-risk families $(\mathrm{n}=216)$ with one parent with bipolar disorder suggest that anxiety disorder may be a reliable antecedent of mood disorders [24]. Additionally, a review of several independent prospective longitudinal high-risk studies led to the convergent observation that childhood anxiety and depressive disorders are typical precursors of a later onset of bipolar disorder while, contrary to previous assumptions, easy annoyance, temper tantrums and ADHD symptoms are not [9].

In conclusion, there are children who meet the classical bipolar disorder criteria. These children frequently present with anxiety disorders and depression before the onset of first manic episodes. Episodic irritability, combined with further manic symptoms, especially elation, meeting the time criteria of DSM is a valuable diagnostic indicator of bipolar disorder, in children as well as in adults. 


\section{Chronic, non-episodic irritability and short-lived episodes of mania-like symptoms}

While there is a consensus regarding classical cases of bipolar disorder, there is an ongoing debate about the diagnostic classification of those children who present with chronic, non-episodic irritability (that is present at least half of the day on most days), but do not fit into any existing category.

Four options have been discussed over the years: (a) chronic irritability is a developmental presentation of bipolar disorder; (b) chronically irritable children suffer rather from severe ADHD, combined with comorbid ODD; (c) chronic irritability is a completely new diagnostic category and cannot be subsumed under existing categories; and (d) so-called "short-lived episodes of mania-like symptoms", and not chronic irritability, are a developmental presentation of bipolar disorder in children.

\section{Is chronic irritability a developmental presentation of bipolar disorder? The concept of severe mood dysregulation}

In 2003, Leibenluft et al. recommended the distinction between a "narrow" and "broad" bipolar phenotype in order to provide a framework for research on chronic irritability in those children who frequently receive a bipolar disorder diagnosis [25]. The "narrow" phenotype of bipolar disorder corresponds to the classical symptom complex with circumscribed manic episodes meeting the DSM-IV criteria. The "broad" phenotype was operationalized as a clinical syndrome called "severe mood dysregulation" (SMD), and includes the putative symptoms for childhood bipolar disorder. Three core features for SMD were defined as a persistent negative mood, marked hyper-arousal and, above all, chronic, nonepisodic irritability.

The prevalence of the symptom complex of SMD in community-based longitudinal studies is in the range of around 3.3\%, but dropped to about $1 \%$ when impairment was added (Great Smoky Mountain Study [26]). Children suffering from SMD and classical bipolar disorder seem to be equally impaired, as indicated by the amount of psychiatric medication and the number of previous psychiatric hospitalizations [27]. Nevertheless, there may be marked and substantial differences concerning their continuity into adulthood: there is accumulating evidence that childhood SMD increases the risk of depressive disorders [26] and anxiety disorders, but not the risk of bipolar disorder in early adulthood [28].

To examine the possible transition to classical mania in children diagnosed with SMD, Stringaris et al. (2010) followed a large group of children with either SMD $(n=84)$ or narrowly defined bipolar disorder $(n=93)$ over 2.5 years. Compared to the group with SMD, the frequency of hypomanic or mixed episodes was 50 times higher in the classical bipolar disorder group [29]. Furthermore, bipolar disorder was more common in the families of children with bipolar disorder than in the families of children with SMD [30,31].

In summary, the family history and the lifetime course of children with SMD support the view that SMD differs substantially from bipolar disorder even though both groups are impaired in multiple domains.

Neuropsychological data from adolescents with SMD and bipolar disorder show both similarities and differences. In a face emotion labeling task, both the SMD and the bipolar disorder group displayed less accuracy [32] and less sensitivity [33] in recognizing facial expressions compared to healthy controls. As irritability can be seen as increased reactivity to negative emotional stimuli, the study of frustration-inducing paradigms might be valuable. Rich et al. paired a computerized attention task with electroencephalography (EEG) recordings of eventrelated potentials (ERPs) and were able to show differences between the two groups in terms of executive attention (with more impairment in the bipolar disorder group) and in the initial state of attention (with higher impairment in the SMD group) [34]. Dickstein et al. found impaired cognitive flexibility in a functional magnetic resonance imaging (fMRI) reversal learning task in both a bipolar disorder group and an SMD group [35]. In a more recent study using a similar paradigm, results pointed towards a decrease in caudate activation in bipolar disorder and SMD groups versus healthy controls, but the SMD group displayed a higher increase in inferior frontal gyrus activation compared to subjects with bipolar disorder [36].

In conclusion, recent findings suggest neurophysiological and neuropsychological impairments and behavioral deficits in both bipolar disorder and SMD, whereas the neural mechanisms of the dysfunction seem to differ between the groups.

\section{Do chronically irritable children suffer from "severe ADHD”?}

Evidently, there is a considerable symptomatic overlap of bipolar symptoms, such as distractibility, excessive talking and reduced social inhibition with other disorders, in particular ADHD $[37,38]$. On the other hand, mood dysregulation is frequent in severe ADHD, with prevalence rates in clinic-based studies between 24 and $50 \%$ [39]. The combination of ADHD and mood 
dysregulation is highly persistent throughout the lifespan and emotional symptoms are a major contributor to impairment in multiple domains [40]. Although experienced clinicians are aware of the relevance of emotional symptoms in the clinical course of the disorder, these symptoms have no longer been captured in our diagnostic criteria for ADHD since the publication of DSM-III, where they were among the cardinal symptoms. Instead, a comorbid depressive or oppositional defiant diagnosis is frequently assigned.

Children meeting the criteria for SMD are also significantly more likely to receive an additional diagnosis, such as ODD or conduct disorder and ADHD [26]. While "classical" bipolar disorder can be easily distinguished from ADHD (as the illness course is episodic, in contrast to the chronic course of ADHD), the distinction between SMD and severe ADHD becomes more difficult, in particular as both groups benefit from medication with stimulants [41].

Clearly, there is a group of severely impaired, chronically irritable children whose symptoms overlap with bipolar disorder and ADHD, but who do not meet the criteria for either diagnosis according to the present nosology. Do these children suffer from a potentially new disorder?

\section{Is chronic irritability a new diagnostic category?}

This issue was explicitly addressed in May 2013 when a new diagnostic category "disruptive mood dysregulation disorder" (DMDD) was introduced in DSM-5. DMDD is almost completely based on the criteria for SMD and includes a persistently irritable mood for at least 12 months as well as severe recurrent temper outbursts at least three times a week - manifested verbally and/or behaviorally that are grossly out of proportion to the situation and the developmental level. The diagnosis requires the presence of the symptoms in at least two of three settings (i.e. in school, at home, with peers) and severe impairment in at least one setting. Several other mental disorders (e.g. bipolar disorder, autism spectrum disorder, post-traumatic stress disorder, separation anxiety disorder, major depressive disorder), substance abuse or other medical or neurological conditions have to be excluded (for full criteria see DSM-5 [15]).

The appearance of DMDD was criticized by experts [42] and the public alike. The main concern is that the introduction of a new diagnostic category might lead to a pathologizing of "normal" children. Nevertheless, so far, DMDD does not seem to be very common. On a positive note, the new category might provide a diagnostic home to a group of children formerly described as "diagnostic orphans" [43], who do not meet the criteria for any psychiatric diagnosis, but display both affective symptoms and ADHD features and show an overall impairment in multiple domains. Moreover, DMDD might help to avoid a misdiagnosis of bipolar disorder. By placing the diagnosis in the depression section, the longitudinal course of irritability with the risk of developing depressive disorder later in life has been taken into account. Copeland et al. recently reported prevalence rates of DMDD ranging from $0.8 \%$ to $3.3 \%$ in two community-based samples [44]. Children meeting the DMDD criteria showed severe impairment in several domains, suffered more often from comorbidities like ODD, ADHD and depression, and were more likely to come from socially disadvantaged families. The high overlap of DMDD with other disorders was also shown by Axelson et al. [45] in a clinically referred sample, in which almost all children (96\%) with the DMDD phenotype also met the criteria for ODD and 77\% met the criteria for ADHD and ODD.

At present, it is not possible to draw a firm conclusion on whether chronic irritability really is a new diagnostic category. Initial findings suggest that DMDD is a diagnosis that is often given to severely impaired children with several comorbidities, in particular ADHD, ODD and depressive disorder.

\section{If chronic irritability is not a developmental presentation of bipolar disorder, what about short-lived episodes of mania-like symptoms?}

The Course and Outcome of Bipolar Youth (COBY) study [46] represents another research-oriented approach to define the subpopulation of emotionally disturbed children with episodes lasting for less than four consecutive days.

Over a period of 5 years, Birmaher et al. followed three groups of children who fulfilled the symptom and impairment criteria for bipolar disorder but differed in the length of the manic episodes: children with episodes lasting for $>7$ days (BD-I, $\mathrm{n}=255)$; children with episodes lasting for 4-7 days (BD-II, $\mathrm{n}=30$ ); and children with episodes lasting for 1-4 days, usually diagnosed with bipolar disorder not otherwise specified (BD-NOS, $\mathrm{n}=153$ ). The three groups did not differ in terms of the age at onset, the duration of illness, the lifetime rates of comorbid psychiatric disorders, and the prevalence of suicidal ideation. Nevertheless, the BD-I group displayed greater overall functional impairment, higher rates of psychiatric hospitalization, psychosis and suicide attempts and a shorter mean time to recovery than the $\mathrm{BD}-\mathrm{NOS}$ group. At the 4-year follow-up, 38\% [47] of the BD-NOS youths had converted to BD-I and BD-II, while this figure lay at 
$45 \%$ [48] after 5 years, with the strongest predictor of conversion being a family history of mania or hypomania.

Despite these remarkable conversion rates, it remains unclear which cases of BD-NOS actually converted, as the authors did not distinguish between cases with very short ( $<1$ day) episodes and episodes closer to the 4-day DSM-IV limit [49]. Additionally, further examinations of the COBY intake data revealed that $90 \%$ of the participants presented with elation or combined elation and irritability, and only $10 \%$ showed irritability as the only emotional core symptom [50].

Taken together, the findings suggest that brief duration hypomania may predict the future development of bipolar disorder, particularly in those with a positive family history of mania, but more research is clearly needed to verify these findings in independent studies.

\section{Implications for treatment}

There is accumulating evidence regarding the treatment of classical bipolar cases with mood-stabilizing antipsychotics, lithium or mood stabilizers $[51,52]$. Since experience of treatment in childhood and adolescence is limited, with less robust data on eventual side effects, treatment on a careful risk/benefit analysis is warranted. Recent studies suggest that second generation antipsychotics, such as risperidones, olanzapine, aripiprazole and quetiapine may be more efficacious than traditional mood stabilizers with $66 \%$ response rates for mania/mixed symptoms in double-blind studies [53] and $68.5 \%$ for risperidone compared with $35.6 \%$ for lithium and $24 \%$ for divalproex sodium [52]. So far, only a few studies have evaluated the effects of antimanic medication in children younger than age 10. For this reason, the Food and Drug Administration (FDA) has approved several antipsychotics for acute treatment for 10-17 year olds [17].

To date, only a small number of studies have investigated treatment options for SMD. In one study of inpatients with SMD, lithium appeared to have no beneficial effects [54]. Other approaches favored the use of stimulant medication, particularly due to the high comorbidity with ADHD. Waxmonsky et al. showed a significant improvement, not only of ADHD and oppositional symptoms, such as distractibility and temper outbursts, but also of mood symptoms. Pharmacotherapy was tolerated well and did not trigger manic symptoms [41].

In order to develop a better affect regulation, cognitive behavioral therapy can be useful, as well as psychoeducation, parenting programs and a close educational cooperation between school and family. Waxmonsky et al. recently developed a novel group therapy program with concurrent sessions for children and parents, which was found to reduce suicidal ideation in children and improve the quality of parenting behavior [55].

To date, there have been no trials regarding the treatment of short-lived episodes of mania-like symptoms, and the relationship with classical mania remains unclear [56]. Thus, an extrapolation of treatment evidence from bipolar cases cannot be recommended in general. Bottom-line treatment will depend on the predominant symptoms and the degree of impairment.

\section{Conclusions and unresolved questions}

A considerable amount of evidence suggests that nonepisodic irritability is not a developmental presentation of mania, and frequently leads to anxiety disorder and depression in adulthood. At present, the diagnostic status of short-lived manic episodes is still unclear. Hence, bipolar disorder should only be diagnosed in the presence of manic or hypomanic episodes in line with the diagnostic criteria [57].

With the introduction of DMDD as a new category, the demarcation between chronic irritability and bipolar disorder was underlined. Nevertheless, open questions remain concerning the validity of the new diagnosis. Only longitudinal studies will conclusively demonstrate whether children with these symptoms really are suffering from a new condition or whether they are suffering from severe forms of widely known psychiatric disorders, such as ADHD, ODD or conduct disorder, or combinations thereof $[43,38]$.

The inclusion of DMDD in DSM-5 also gives rise to more general questions regarding how best to classify disease. Lately, the National Institutes of Mental Health (NIMH) has moved away from the categorical DSM criteria by developing more dimensional "research domain criteria" [58] in order to collect data for a new nosology.

This alternative view, advocating the treatment of irritability as a dimension rather than a category, has also been addressed by Stringaris et al. and has led to the development of "the affective reactivity index" [59]. However, although this seems to be an attractive new model, it will not spare clinicians from introducing thresholds and ultimately making the black or white decision of whether to treat or not treat.

In the future, carefully designed longitudinal studies will help to clarify the actual impact and stability of the newly established diagnosis of DMDD and investigate how children with this diagnosis develop in their adult lives. 


\begin{abstract}
Abbreviations
ADHD, attention deficit hyperactivity disorder; BD-NOS, bipolar disorder not otherwise specified; COBY, Course and Outcome of Bipolar Youth; DMDD, disruptive mood dysregulation disorder; DSM, Diagnostic and statistical manual of mental disorders; ODD, oppositional deficit disorder; SMD, severe mood dysregulation.
\end{abstract}

\section{Disclosures}

The authors declare that they have no disclosures.

\section{References}

I. Blader JC, Carlson GA: Increased rates of bipolar disorder diagnoses among U.S. child, adolescent, and adult inpatients, 1996-2004. Biol Psychiatry 2007, 62:107-I4.

\section{FlOOOPrime}

\section{RECOMMENDED}

2. Moreno $C$, Laje $G$, Blanco $C$, Jiang $H$, Schmidt $A B$, Olfson $M$ : National trends in the outpatient diagnosis and treatment of bipolar disorder in youth. Arch Gen Psychiatry 2007, 64:1032-9.

\section{FlOOOPrime}

\section{RECOMMENDED}

3. Holtmann M, Bölte S, Poustka F: Rapid increase in rates of bipolar diagnosis in youth: "true" bipolarity or misdiagnosed severe disruptive behavior disorders? Arch Gen Psychiatry 2008, 65:477.

4. Holtmann M, Duketis E, Poustka L, Zepf FD, Poustka F, Bölte S: Bipolar disorder in children and adolescents in Germany: national trends in the rates of inpatients, 2000-2007. Bipolar Disord 2010, 12:155-63.

5. Lázaro L, Castro-Fornieles J, de la Fuente, José Eugenio, Baeza I, Morer A, Pàmias M: Differences between prepubertal- versus adolescent- onset bipolar disorder in a Spanish clinical sample. Eur Child Adolesc Psychiatry 2007, 16:510-6.

6. Van Meter, Anna R, Moreira, Ana Lúcia R, Youngstrom EA: Metaanalysis of epidemiologic studies of pediatric bipolar disorder. J Clin Psychiatry 201I, 72:1250-6.

7. Olfson M, Blanco C, Liu L, Moreno C, Laje G: National trends in the outpatient treatment of children and adolescents with antipsychotic drugs. Arch Gen Psychiatry 2006, 63:679-85.

8. Kim-Cohen J, Caspi A, Moffitt TE, Harrington H, Milne BJ, Poulton R: Prior juvenile diagnoses in adults with mental disorder: developmental follow-back of a prospective-longitudinal cohort. Arch Gen Psychiatry 2003, 60:709-17.

9. Duffy $A$ : The nature of the association between childhood ADHD and the development of bipolar disorder: a review of prospective high-risk studies. Am J Psychiatry 20I2, 169:1247-55

\section{FlOOOPrime}

\section{RECOMMENDED}

10. Perlis RH, Miyahara S, Marangell LB, Wisniewski SR, Ostacher M, DelBello MP, Bowden CL, Sachs GS, Nierenberg AA: Long-term implications of early onset in bipolar disorder: data from the first 1000 participants in the systematic treatment enhancement program for bipolar disorder (STEP-BD). Biol Psychiatry 2004, 55:875-81.

\section{FlOOOPrime}

\section{RECOMMENDED}

II. Post RM, Leverich GS, Kupka RW, Keck PE, McElroy SL, Altshuler LL, Frye MA, Luckenbaugh DA, Rowe M, Grunze H, Suppes T, Nolen WA: Early-onset bipolar disorder and treatment delay are risk factors for poor outcome in adulthood. J Clin Psychiatry 2010, 71:864-72.

\section{FlOOOPrime

12. Wozniak J, Biederman J, Kiely K, Ablon JS, Faraone SV, Mundy E, Mennin D: Mania-like symptoms suggestive of childhood-onset bipolar disorder in clinically referred children. J Am Acad Child Adolesc Psychiatry 1995, 34:867-76.

13. Geller B, Tillman R, Craney JL, Bolhofner K: Four-year prospective outcome and natural history of mania in children with a prepubertal and early adolescent bipolar disorder phenotype. Arch Gen Psychiatry 2004, 6I:459-67.

14. Biederman J, Klein RG, Pine DS, Klein DF: Resolved: mania is mistaken for ADHD in prepubertal children. J Am Acad Child Adolesc Psychiatry 1998, 37:1091-6; discussion 1096-9.

15. Diagnostic and statistical manual of mental disorders: DSM-5. 5th edition. Washington, DC: American Psychiatric Association; 2013.

16. Kowatch RA, Youngstrom EA, Danielyan A, Findling RL: Review and meta-analysis of the phenomenology and clinical characteristics of mania in children and adolescents. Bipolar Disord 2005, 7:483-96.

\section{FlOOOPrime}

RECOMMENDED

17. Diler RS, Birmaher B: Bipolar disorder in children and adolescents. In IACAPAP e-Textbook of Child and Adolescent Mental Health. Edited by Rey JM. Geneva: International Association for Child and Adolescent Psychiatry and Allied Professions; 2014.

18. McClellan J, Kowatch R, Findling RL: Practice parameter for the assessment and treatment of children and adolescents with bipolar disorder. J Am Acad Child Adolesc Psychiatry 2007, 46: I07-25.

\section{FlOOOPrime}

RECOMMENDED

19. Geller B, Tillman R, Bolhofner K, Zimerman B: Child bipolar I disorder: prospective continuity with adult bipolar I disorder; characteristics of second and third episodes; predictors of 8-year outcome. Arch Gen Psychiatry 2008, 65: I I25-33.

\section{FlOOOPrime}

RECOMMENDED

20. Costello EJ, Angold A, Burns BJ, Erkanli A, Stangl DK, Tweed DL: The Great Smoky Mountains Study of Youth. Functional impairment and serious emotional disturbance. Arch Gen Psychiatry 1996, 53:1137-43.

21. Stringaris A, Santosh P, Leibenluft E, Goodman R: Youth meeting symptom and impairment criteria for mania-like episodes lasting less than four days: an epidemiological enquiry. J Child Psychol Psychiatry 2010, 51:31-8.

22. Merikangas KR, He J, Burstein M, Swanson SA, Avenevoli S, Cui L, Benjet C, Georgiades K, Swendsen J: Lifetime prevalence of mental disorders in U.S. adolescents: results from the National Comorbidity Survey Replication-Adolescent Supplement (NCS-A). J Am Acad Child Adolesc Psychiatry 2010, 49:980-9.

23. Lewinsohn PM, Klein DN, Seeley JR: Bipolar disorders in a community sample of older adolescents: prevalence, phenomenology, comorbidity, and course. J Am Acad Child Adolesc Psychiatry 1995, 34:454-63.

24. Duffy A, Horrocks J, Doucette S, Keown-Stoneman C, McCloskey S, Grof $\mathrm{P}$ : Childhood anxiety: an early predictor of mood disorders in offspring of bipolar parents. J Affect Disord 2013, I50:363-9.

\section{FlOOOPrime}

RECOMMENDED

25. Leibenluft E, Charney DS, Towbin KE, Bhangoo RK, Pine DS: Defining clinical phenotypes of juvenile mania. Am J Psychiatry 2003, 160:430-7.

\section{FlOOOPrime}

RECOMMENDED

26. Brotman MA, Schmajuk M, Rich BA, Dickstein DP, Guyer $A E$, Costello EJ, Egger HL, Angold A, Pine DS, Leibenluft E: Prevalence, clinical correlates, and longitudinal course of severe mood dysregulation in children. Biol Psychiatry 2006, 60:99I-7. 
27. Leibenluft E, Cohen P, Gorrindo T, Brook JS, Pine DS: Chronic versus episodic irritability in youth: a community-based, longitudinal study of clinical and diagnostic associations. J Child Adolesc Psychopharmacol 2006, 16:456-66.

28. Stringaris A, Cohen P, Pine DS, Leibenluft E: Adult outcomes of youth irritability: a 20-year prospective community-based study. Am J Psychiatry 2009, 166:1048-54.

\section{FlOOOPrime
RECOMMENDED}

29. Stringaris A, Baroni A, Haimm C, Brotman M, Lowe CH, Myers F, Rustgi E, Wheeler W, Kayser R, Towbin K, Leibenluft E: Pediatric bipolar disorder versus severe mood dysregulation: risk for manic episodes on follow-up. J Am Acad Child Adolesc Psychiatry 2010, 49:397-405.

\section{FlOOOPrime}

\section{RECOMMENDED}

30. Brotman MA, Kassem L, Reising MM, Guyer AE, Dickstein DP, Rich BA, Towbin KE, Pine DS, McMahon FJ, Leibenluft E: Parental diagnoses in youth with narrow phenotype bipolar disorder or severe mood dysregulation. Am J Psychiatry 2007, I64: | 238-4I.

\section{FlOOOPrime RECOMMENDED}

31. Leibenluft E: Severe mood dysregulation, irritability, and the diagnostic boundaries of bipolar disorder in youths. $\mathrm{Am} J$ Psychiatry 2011, 168: 129-42.

\section{FlOOOPrime \\ RECOMMENDED}

32. Guyer AE, McClure EB, Adler AD, Brotman MA, Rich BA, Kimes AS, Pine DS, Ernst M, Leibenluft E: Specificity of facial expression labeling deficits in childhood psychopathology. J Child Psychol Psychiatry 2007, 48:863-7I.

\section{FlOOOPrime \\ RECOMMENDED}

33. Rich BA, Grimley ME, Schmajuk M, Blair KS, Blair R J R, Leibenluft E: Face emotion labeling deficits in children with bipolar disorder and severe mood dysregulation. Dev Psychopathol 2008, 20:529-46.

\section{FlOOOPrime \\ RECOMMENDED}

34. Rich BA, Schmajuk M, Perez-Edgar KE, Fox NA, Pine DS, Leibenluft E: Different psychophysiological and behavioral responses elicited by frustration in pediatric bipolar disorder and severe mood dysregulation. Am J Psychiatry 2007, 164:309-17.

\section{FlOOOPrime}

35. Dickstein DP, Finger EC, Skup M, Pine DS, Blair, JR, Leibenluft E: Altered neural function in pediatric bipolar disorder during reversal learning. Bipolar Disord 2010, 12:707-19.

\section{FlOOOPrime}

36. Adleman NE, Kayser R, Dickstein D, Blair, R James R, Pine $D$, Leibenluft E: Neural correlates of reversal learning in severe mood dysregulation and pediatric bipolar disorder. J Am Acad Child Adolesc Psychiatry 201 I, 50:1 I73-I I85.e2.

\section{FlOOOPrime}

\section{RECOMMENDED}

37. Zepf FD: Attention deficit-hyperactivity disorder and earlyonset bipolar disorder: two facets of one entity? Dialogues Clin Neurosci 2009, 1 I:63-72.

38. Zepf FD, Holtmann M: Disruptive mood dysredulation disorder. In In IACAPAP e-Textbook of Child and Adolescent Mental Health. Edited by Rey JM. Geneva: International Association for Child and Adolescent Psychiatry and Allied Professions; 2014.

39. Shaw P, Stringaris A, Nigg J, Leibenluft E: Emotion dysregulation in attention deficit hyperactivity disorder. Am J Psychiatry 2014, I71:276-93.
40. Riley AW, Spiel G, Coghill D, Döpfner M, Falissard B, Lorenzo MJ, Preuss $U$, Ralston $S$ J: Factors related to health-related quality of life (HRQoL) among children with ADHD in Europe at entry into treatment. Eur Child Adolesc Psychiatry 2006, I5(Suppl I):I38-45.

\section{FIOOOPRime}

4I. Waxmonsky J, Pelham WE, Gnagy E, Cummings MR, O'Connor B, Majumdar A, Verley J, Hoffman MT, Massetti GA, Burrows-MacLean L, Fabiano GA, Waschbusch DA, Chacko A, Arnold FW, Walker KS, Garefino AC, Robb JA: The efficacy and tolerability of methylphenidate and behavior modification in children with attention-deficit/hyperactivity disorder and severe mood dysregulation. J Child Adolesc Psychopharmacol 2008, 18:573-88.

\section{FlOOOPrime} RECOMMENDED

42. Axelson DA, Birmaher B, Findling RL, Fristad MA, Kowatch RA Youngstrom EA, Arnold EL, Goldstein BI, Goldstein TR, Chang KD, DelBello MP, Ryan ND, Diler RS: Concerns regarding the inclusion of temper dysregulation disorder with dysphoria in the Diagnostic and Statistical Manual of Mental Disorders, Fifth Edition. J Clin Psychiatry 20II, 72:1257-62.

43. Carlson GA: Who are the children with severe mood dysregulation, a.k.a. "rages"? . Am J Psychiatry 2007, I64: | | 40-2.

44. Copeland WE, Angold A, Costello EJ, Egger H: Prevalence, comorbidity, and correlates of DSM-5 proposed disruptive mood dysregulation disorder. Am J Psychiatry 2013, 170:173-9.

\section{FlOOOPrime}

45. Axelson D, Findling RL, Fristad MA, Kowatch RA, Youngstrom EA, Horwitz SM, Arnold LE, Frazier TW, Ryan N, Demeter C, Gill MK, Hauser-Harrington JC, Depew J, Kennedy SM, Gron BA, Rowles BM, Birmaher B: Examining the proposed disruptive mood dysregulation disorder diagnosis in children in the Longitudinal Assessment of Manic Symptoms study. J Clin Psychiatry 2012, 73:1342-50.

\section{FlOOOPrime}

\section{RECOMMENDED}

46. Birmaher B, Axelson D, Strober M, Gill MK, Valeri S, Chiappetta L, Ryan N, Leonard H, Hunt J, lyengar S, Keller M: Clinical course of children and adolescents with bipolar spectrum disorders. Arch Gen Psychiatry 2006, 63:175-83.

\section{FIOOOPRime
RECOMMENDED}

47. Birmaher B, Axelson D, Goldstein B, Strober M, Gill MK, Hunt J, Houck P, Ha W, lyengar S, Kim E, Yen S, Hower H, EspositoSmythers C, Goldstein T, Ryan N, Keller M: Four-year longitudinal course of children and adolescents with bipolar spectrum disorders: the Course and Outcome of Bipolar Youth (COBY) study. Am J Psychiatry 2009, 166:795-804.

\section{FlOOOPrime}

48. Axelson DA, Birmaher B, Strober MA, Goldstein BI, Ha W, Gill MK, Goldstein TR, Yen S, Hower H, Hunt Jl, Liao F, lyengar S, Dickstein D, Kim E, Ryan ND, Frankel E, Keller MB: Course of subthreshold bipolar disorder in youth: diagnostic progression from bipolar disorder not otherwise specified. J Am Acad Child Adolesc Psychiatry 201I, 50:100I-16.e3.

49. Mikita N, Stringaris A: Mood dysregulation. Eur Child Adolesc Psychiatry 2013, 22(Suppl I):SII-6.

50. Hunt J, Birmaher B, Leonard H, Strober M, Axelson D, Ryan N, Yang M, Gill M, Dyl J, Esposito-Smythers C, Swenson L, Goldstein B, Goldstein T, Stout R, Keller M: Irritability without elation in a large bipolar youth sample: frequency and clinical description. J Am Acad Child Adolesc Psychiatry 2009, 48:730-9.

5I. Correll CU, Sheridan EM, DelBello MP: Antipsychotic and mood stabilizer efficacy and tolerability in pediatric and adult patients with bipolar I mania: a comparative analysis of 
acute, randomized, placebo-controlled trials. Bipolar Disord 2010, I2:|||6-4|.

52. Geller B, Luby JL, Joshi P, Wagner KD, Emslie G, Walkup JT, Axelson DA, Bolhofner K, Robb A, Wolf DV, Riddle MA, Birmaher B, Nusrat N, Ryan ND, Vitiello B, Tillman R, Lavori P: A randomized controlled trial of risperidone, lithium, or divalproex sodium for initial treatment of bipolar I disorder, manic or mixed phase, in children and adolescents. Arch Gen Psychiatry 2012, 69:5I5-28.

\section{FlOOOPrime}

53. Liu HY, Potter MP, Woodworth KY, Yorks DM, Petty CR, Wozniak JR, Faraone SV, Biederman J: Pharmacologic treatments for pediatric bipolar disorder: a review and meta-analysis. J Am Acad Child Adolesc Psychiatry 20I I, 50:749-62.e39.

\section{FlOOOPrime}

\section{FIOPPOM}

54. Dickstein DP, Towbin KE, Van Der Veen, Jan Willem, Rich BA, Brotman MA, Knopf L, Onelio L, Pine DS, Leibenluft E: Randomized double-blind placebo-controlled trial of lithium in youths with severe mood dysregulation. J Child Adolesc Psychopharmacol $2009,19: 61-73$
55. Waxmonsky JG, Wymbs FA, Pariseau ME, Belin PJ, Waschbusch DA, Babocsai L, Fabiano GA, Akinnusi OO, Haak JL, Pelham WE: A novel group therapy for children with ADHD and severe mood dysregulation. J Atten Disord 2013, 17:527-4I.

\section{FlOOOPrime

RECOMMENDED

56. Stringaris A, Stahl D, Santosh P, Goodman R: Dimensions and latent classes of episodic mania-like symptoms in youth: an empirical enquiry. J Abnorm Child Psychol 201I, 39:925-37.

57. Baroni A, Lunsford JR, Luckenbaugh DA, Towbin KE, Leibenluft E: Practitioner review: the assessment of bipolar disorder in children and adolescents. J Child Psychol Psychiatry 2009, 50:203-15.

FIOOOPrime

58. Insel TR: The NIMH Research Domain Criteria (RDoC) Project: precision medicine for psychiatry. Am J Psychiatry 2014, 171:395-7.

59. Stringaris A, Goodman R, Ferdinando S, Razdan V, Muhrer E, Leibenluft E, Brotman MA: The Affective Reactivity Index: a concise irritability scale for clinical and research settings. J Child Psychol Psychiatry 2012, 53:I 109-17. 